\title{
Prevalence, Identification and Antibiotic Susceptibility of Enterococcus Species Isolated from Chicken and Pigeon Meat in Gazipur Area of Bangladesh
}

\author{
Avijit Banik, Noor Mohammad, Tanzina Akter, Kaniz Fatema*, Maruf Abony \\ Department of Microbiology, Primeasia University, HBR Tower, Dhaka, Bangladesh \\ Email: *kaniz_0309@yahoo.com
}

How to cite this paper: Banik, A., Mohammad, N., Akter, T., Fatema, K. and Abony, M. (2018) Prevalence, Identification and Antibiotic Susceptibility of Enterococcus Species Isolated from Chicken and Pigeon Meat in Gazipur Area of Bangladesh. Open Journal of Medical Microbiology, 8, 74-83.

https://doi.org/10.4236/ojmm.2018.83007

Received: August 9, 2018

Accepted: September 15, 2018

Published: September 18, 2018

Copyright $\odot 2018$ by authors and Scientific Research Publishing Inc. This work is licensed under the Creative Commons Attribution International License (CC BY 4.0).

http://creativecommons.org/licenses/by/4.0/

\begin{abstract}
Aims: The aims of this work undertaken to investigate and identify the prevalence of Enterococcus spp isolated from Chicken and pigeon meat and determine the using antibiotics sensitivity against isolates for human safety. This study was conducted in center of excellence lab in Microbiology Department of Primeasia University, Banani, Dhaka-1213, Bangladesh during August, 2017 to March, 2018. Methodology and Results: Twenty four samples were collected in pre-sterilized zip-lock bags from different Gazipur area in different local meat vendors. All samples were transported to the Microbiology Laboratory of Primeasia University and analyzed according to standard analysis methods. Total viable count (TVC) and Total Enterocooci count (TEC) were estimated by using plate count agar (PCA) and Bile Esculineagar plates respectively. Various Selective media and Biochemical tests were used for presumptive isolation and identification. Kirby-Bauer disc diffusion method on Mueller Hinton agar media was used for the determination of sensitivity of the isolated strains to commonly prescribe antibiotics. A total of 24 meat samples were examined of which $92 \%$ were positive to Enterococcus spp whereas $62.5 \%$ were Chicken and $32.5 \%$ pigeon. The counts of enterococci range of 0 - $6.49 \log \mathrm{CFU} / \mathrm{gm}$ in chicken and $4.4-6.4 \log \mathrm{CFU} / \mathrm{gm}$ in pigeon. 22 isolates of enterococci, $77.27 \%$ were resistance to Azithromycin, $54.55 \%$ to Nalidixic acid and $50 \%$ to Sulfamethoxazole. We found high sensitivity of antimicrobial agent against to Imipenem (100\%), Ciprofloxacin $(81.81 \%)$ and (77.27\%) both Tetracycline and Erythromycin. Conclusion: Significance and Impact of the study: The study result expressed that awareness of the meat pathogen and when consumption of meat was well cooked of our daily life.
\end{abstract}




\section{Keywords}

Enterococcus, Enterococci from Chicken and Pigeon, Antibiotic Sensitivity, Gazipur Area in Bangladesh

\section{Introduction}

Enterococcus spp. are representative of the key genera of lactic acid bacteria (LAB), with a wide distribution in the environment and also found in a variety of food sources, such as meat, vegetables, milk, Cheese, water surface and plants [1]. They are gram positive, non spore forming facultative anaerobes and also lack catalase activity, having tolerance of a high restrictive condition, such as temperature $\left(10^{\circ} \mathrm{C}-45^{\circ} \mathrm{C}\right),{ }_{\mathrm{p}} \mathrm{H}(9.6)$, hyperosmolarity $(6.5 \% \mathrm{NaCl})$ and prolonged desiccation [2] [3]. Enterococci are mostly inhabitants in gastrointestinal tract (GIT) of humans and animals, but recent reports have suggested their presence in wide distribution in environment and diverse ecological niches [4] [5]. A wide variety of human infections are occurring by the most frequent causative agents Enterococcus spp which are infect Blood stream, heart, abdomen, urinary tract etc, with $70 \%-80 \%$ of the responsible for being Enterococcus faecalis of the cases [6] and also as an infected nosocomial infection like ear and eyes infections, meningitis, burns wounds and abscess, paranasal sinuses etc. [7]. The key contributor for acquiring and disseminating antibiotic resistance against Enterococcus spp. has been isolated from poultry meat, feed and other food-chain stuffs [8]. Poultry, which are infected by wide range of Enterococcus spp. such as Ent. cecorum causes arthritis, spondylitis, femoral head necrosis, osteomyelitis, lameness and paralysis of broilers [9] [10].

Bangladesh is one of the key players in the South Asian livestock industry; especially in poultry industry [11]. Poultry industries play an important role in poverty alleviation and economic development of Bangladesh. In Bangladesh, out of a total animal protein supplies approximately $37 \%$ comes from poultry meat [12]. According to WHO-FAO joint survey, people in Bangladesh consume $15.23 \mathrm{~kg}$ meat per person in a year and poultry provided $35.25 \%$ of total meat supply [13].

In 2015 to 2016, Enterococcus faecalis and Enterococcus faecium were isolated from clinical infection (Urine, Pus and wound swab) in Mymensingh medical college hospital [14]. In most cases, the birds are not sick and the production is not affected. The degree of illness depends on factors of both the host and the bacteria. However, No surveillance data of Enterococcus spp. associated with poultry have been made in Bangladesh.

Thus, our present study was designed to comprehensive microbial status on Enterococcus spp. associated with livestock (poultry and pigeon meat) and their drug sensitivity status against enterococci in Gazipur district, Bangladesh. Our results indisputably indicate that a serious promise is required to deal with pathogenic enterococci associated with poultry and pigeon meat for preventing 
transmission of infectious agent to humans.

\section{Materials and Methods}

\subsection{Sample Collection and Enrichment Procedure}

A total of 24 meat Samples were collected different location of Gazipur areas. Samples included 15 poultry chicken and 9 pigeon meat samples, which were purchased from the different local meat shops at Gazipur area during August, 2017 to March, 2018.Gazipur area is the most poultry (chicken and pigeon) supplying area around Dhaka city, mymensingh and nearest area in Gazipur. Samples were collected the different location of the Gazipur areas based on following some citrate such as area most repeated customer shop, wholesales farms and most customers gathering market. Using sample in this experiment, chicken weight were almost (1 - 1.5) kg and pigeon (300 - 500) gm. All samples were kill by butcher in the meat shop and washed and clean the outer layer of feather in samples and other dirt matters. After that sample were washed by the fresh water and clean blood. All Samples meat were collected in pre-sterilized Stomacher bags $(165 \mathrm{~mm} \times 150 \mathrm{~mm} \times 0.55 \mathrm{~mm})$ and all samples were transported to the Microbiology (Centre of Excellence) Laboratory of Primeasia University at the earliest convenience for processing and further assessment as Table 1.

\subsection{Microbiological Analysis}

After taking sample in laboratory for further analysis, each sample were transferred $10 \mathrm{~g}$ in $90 \mathrm{ml}$ sterile Nutrient broth media (Oxoid Ltd, Hampshire, England) in sterile Borosilicate Media Bottles and incubated $37^{\circ} \mathrm{C}$ for 4 hours. Every 30 minutes later, the incubated bottle was shaken for homogenized in manually by head in $5 \mathrm{~min}$. Total Viable Count (TVC) and Total Enterococcus count (TEC) of samples were counted on plate count agar and Bile Esculine Agar media respectively (Oxoid Ltd, Hampshire, UK \& HiMedia Laboratories, Mumbai, India). According to manufacturer's instruction media were prepared. All media were sterilized by autoclave at $121^{\circ} \mathrm{C}$ for 15 minutes. One $\mathrm{ml}$ of incubated sample was diluted in $9 \mathrm{ml}$ sterile normal saline water $(0.85 \% \mathrm{NaCl})$. After dilution, Decimal dilutions were prepared up to $10^{-6}$ and after appropriate dilution, $100 \mu \mathrm{l}$ homogenate of each samples was inoculated in respective media and using spread method by sterile glass spreader. Inoculated plates were kept in an incubator at $37^{\circ} \mathrm{C}$ for overnight growth. After incubation the number of visible colonies upon media surface were counted and expressed as logarithm of colony forming unit (log CFU) per gram of samples.

Table 1. Name of the location area and sample size in Gazipur area.

\begin{tabular}{cccc}
\hline Name of the area in Gazipur & Chicken sample & Name of the area in Gazipur & Pigeon Sample \\
\hline Gazipur Chowrasta area & 4 & Kanabari bazar area & 3 \\
Joydepur area & 4 & Salna bazaar area & 6 \\
Tongi Bazar area & 7 &
\end{tabular}




\subsection{Isolation and Identification of Enterococcus sp}

Isolated Enterococcus Count of sample in Bile Esculine Agar media respectively than collected pure colony the count plate and again using four way streaking method in fresh Bile Esculine Agar media (HiMedia Laboratories, Mumbai, India) for isolated Enterococcus spp and was incubated at $37^{\circ} \mathrm{C}$ for 20 to 24 hours and after incubation period isolated was showing Black colony. Enterococcus spp were given black colony in BEA medium and presumptive identification of each colony came from biochemical tests and Microscopic profiling (Figure 1).

\subsection{Biochemical Test}

Pure colonies from nutrient agar (NA) plates were subjected for biochemical tests such as Triple sugar iron agar (TSI), Simmons citrate agar media, MR-VP media for Methyl red and Voges-Proskeur test, SIM media for Indole and motility test, Oxidase, Catalase test were done [15].

\subsection{Antibiotics Susceptibility Test}

Susceptibility of Isolated Enterococcus spp. was tested to different antimicrobial agents was measured in vitro by the Kirby-Bauer method [16]. It allowed determination of the efficiency of antibiotic by measuring the diameter of the zone of inhibition that outcome from diffusion of the antimicrobial agent into the medium surrounding the disc. The ranges of susceptible antibiotic of the isolates were measured using commercially purchased discs (Oxoid Ltd, Hampshire, England) on Muller-Hinton Agar (Oxoid Ltd, Hampshire, England). Commercially available antibiotics used in this experiment included Tetracyclin $30 \mu \mathrm{g}$ (TE), Azithromycin $15 \mu \mathrm{g}$ (AZM), Sulphamethoxazole $25 \mu \mathrm{g}$ (SXT), Ciprofloxacin $5 \mu \mathrm{g}$ (CIP), Erythromycin $15 \mu \mathrm{g}$ (E), Nalidixic Acid $30 \mu \mathrm{g}$ (NA), Chloramphenicol $30 \mu \mathrm{g}(\mathrm{C})$, Imipenem $10 \mu \mathrm{g}$ (IMI) [17].

\subsection{Statistical Analysis}

Microbiological data were transformed into logarithms of number of colony forming units (CFU/gm) and were subjected to analysis of variance (ANOVA). Means and standard deviations were calculated, and, when $F$-values were significant

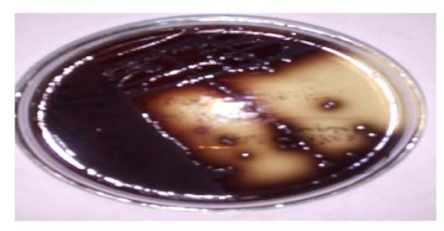

Bile Esculine Agar media

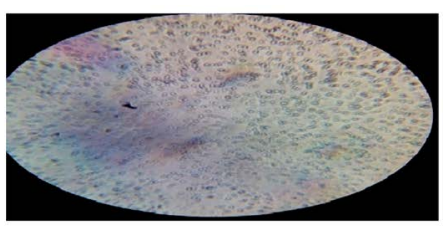

Gram staining of Enterococcus isolation

\begin{tabular}{|c|c|}
\hline \multicolumn{2}{|c|}{ Main characteristics of the Enterococcus $S p$} \\
\hline Colony Color of BEM Ager media & Blacking colony color in the media \\
\hline Colony shape in Microscope & Cocci \\
\hline Gram stain & Positive, Violet \\
\hline
\end{tabular}

Figure 1. A. Selective media for Enterococcus sp. identification; B. Microscopic Observation. 
at the $P<0.05$ level, mean differences were Significant by the Least Significant Differences (LSD) procedure [18].

\section{Result}

In this study, all most all Samples were showed positive Enterococcus spp. in the lower levels of contamination found in meat. There were 13 chicken and 9 pigeon meat found the positive result in 24 meat samples in the different location in Gazipur area Figure 2.

It is probably related with different sampling areas of poultry and Pigeon. The total bacterial count (TBC) and count of enterococci presented by plotting the $\log 10$ value of CFU/gm in poultry and pigeon are showed in Table 2. Poultry and pigeon had significantly $(\mathrm{p}<0.05)$ higher number of TBC than enterococci count. The differences among TBC in both meat from different abattoirs were collection statistically significant $(\mathrm{P}<0.05)$, which could be explained by relevant pre-slaughter conditions which include those condition (shower, transport distance, sanitary and chilling conditions). In this slaughter condition of the abattoirs increase the total bacterial load in samples.

After slaughtering the both samples (Chicken and pigeon) washed to clean them of dirt and fecal matters. Such matter as well as contaminant present in water may affect the bacteriological load on the meat sample. Based on the transport distance after slaughter TBC of meat sample will Change.

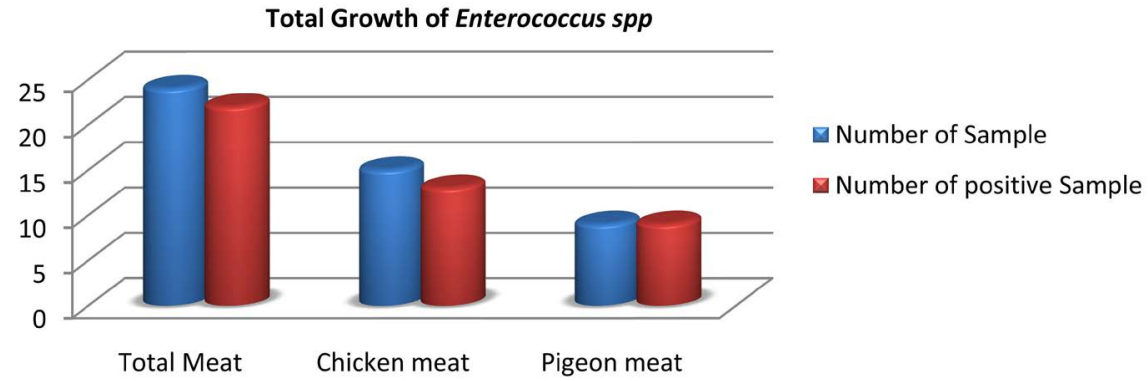

Figure 2. Presence of total growth of positive Enterococcus Spp. in Meat sample from Gazipur area.

Table 2. The total bacterial count and count of enterococci in different meat samples.

\begin{tabular}{|c|c|c|c|c|}
\hline & \multicolumn{4}{|c|}{ Count (CFU/gm) } \\
\hline & \multicolumn{2}{|c|}{ Total Bacterial count } & \multicolumn{2}{|c|}{ Total Enterococcus spp. count } \\
\hline & Poultry & Pigeon & Poultry & Pigeon \\
\hline $\mathrm{X}$ & 6.34 & 6.18 & 4.83 & 5.25 \\
\hline MIN & 5.96 & 5.85 & 0 & 4.44 \\
\hline MAX & 6.78 & 6.45 & 6.49 & 6.4 \\
\hline$S$ & 0.87 & 0.85 & 1.08 & 0.98 \\
\hline
\end{tabular}

Note: $\mathrm{X}=$ values of means, $\mathrm{MIN}=$ Minimum, $\mathrm{MAX}=$ Maximum, $\mathrm{S}=$ Standard deviation. 
Sanitary condition of the poultry slaughter house has significant on the TBC. It may be caused by the unhygienic condition of the butcher, cutting instruments, surrounding environment of the slaughter house, without clean and washed knife slaughter the samples repeatedly. It chilling condition and temperature imbalances are not maintain properly reservation of the samples; it may impact on the increase if the bacterial load counts. E. faecalis predominated in the Gram-positive cocci isolated from chicken samples collected at poultry abattoirs in found FRANZ et al. [19].

In the present study, Enterococcus spp was found in almost $92 \%$ of the chicken and pigeon carcasses analyzed. A total of 22 strains were isolated and indentified. Only 2 isolates were not identified to Enterococcus spp. The total bacterial count (TBC) records 6.78 CFU/gm in joydepur Bazar and 5.85 CFU/gm in pigeon in Konabari Bazar area. Maximum counts of Enterococci of chicken were similar place on TBC and salna Bazar area pigeon showed the maximum Enterocooci count. After the colony morphology in selective media, the presumptive isolation was indicating in target microorganisms. Presence of Black colonies on Bile Esculine agar indicated presumptive Enterococcus spp. isolates on a both meat samples. Most of the isolate showed cocci and diplococci shape in violet positive color in gram straining. Triple sugar iron (TSI) showed carbohydrate fermentation with gas production and $\mathrm{H}_{2} \mathrm{~S}$ from the isolates, whereas IMViC (Indole, Methyl-red, Voges-Proskeur, Citrate) test and also oxidase, catalase and motility indicated identifying for Enterococcus spp (Table 3).

Finally the antibiotic susceptibility patterns of the isolates indicated. In using of Kirby-Bauer method, to determine sensitivity inculcated Muller-Hinton Agar plates were observed. Isolates from meat products identified as Enterococcus spp introduced against eight antibiotics for their susceptibility test. Among the isolates, antibiotics of resistance were detected mainly in Enterococcus spp significantly prevalence of resistant isolates from Azithromycin (78\%), Nalidixic acid (55\%) and Sulfomethoxazole (50\%) detected. Sensitivity pattern of Enterococcus spp. from meat samples as Figure 3.

Isolated enterococci from poultry and pigeon showed resistance to two or more antibiotics such as Azithromycin 84.62\%, Sulfomethoxazole $53.84 \%$ in poultry and $66.67 \%$ in Azithromycin, 55.56\% in Nalidixic acid resistance in pigeon

Table 3. Biochemical profile of bacterial isolates from meat samples.

\begin{tabular}{|c|c|c|c|c|c|c|c|c|c|}
\hline Gram straining & $\begin{array}{c}\text { TSI } \\
\text { Butt Slant Gas }\end{array}$ & $\begin{array}{l}\mathrm{H}_{2} \mathrm{~S} \\
\text { Test }\end{array}$ & $\begin{array}{l}\text { Citrate } \\
\text { Test }\end{array}$ & $\begin{array}{l}\text { MIU } \\
\text { Test }\end{array}$ & $\begin{array}{l}\text { MR } \\
\text { Test }\end{array}$ & $\begin{array}{l}\text { VP } \\
\text { Test }\end{array}$ & $\begin{array}{c}\text { Catalase } \\
\text { Test }\end{array}$ & $\begin{array}{l}\text { Oxidase } \\
\text { Test }\end{array}$ & $\begin{array}{c}\text { Presumptive } \\
\text { organism }\end{array}$ \\
\hline Violet, cocci & $\begin{array}{l}\text { B- Red } \\
\text { S- Red } \\
\text { G: (-) }\end{array}$ & - & - & $\begin{array}{c}\text { M- (-) } \\
\text { I- (-) } \\
\text { U- (-) }\end{array}$ & - & + & - & - & $\begin{array}{c}\text { Enterococcus } \\
\text { spp }\end{array}$ \\
\hline Violet, Diplococci & $\begin{array}{c}\text { B- Yellow } \\
\text { S- Yellow } \\
\text { G- (-) }\end{array}$ & - & + & $\begin{array}{c}\text { M- (-) } \\
\text { I- (-) } \\
\text { U- (-) }\end{array}$ & - & + & & - & Enterococcus spp \\
\hline
\end{tabular}

Note: TSI = Triple Sugar Iron; MIU = Motility, Indole, Urea, MR = Methyl red; VP = Voges-Proskeur. 
isolates. Of 24 isolates of enterococci, $100 \%$ were sensitive in imipenem in both meat samples.88.89\% and $76.92 \%$ were sensitive in ciprofloxacin in pigeon and poultry isolates showed by Figure 4 \& Figure 5.

\section{Discussion}

In the growing and developing industry in Bangladesh, poultry is one of them. In recent decades, poultry industry faces lots of old and new infection of poultry animals in Bangladesh. In recent times, Enterococci are emerged as important pathogens responsible for occurred a serious infection in hospital and also as community acquired infection, whereas it's normally found of the normal intestinal flora of human and animals. In Labadie presented that, the slaughtering

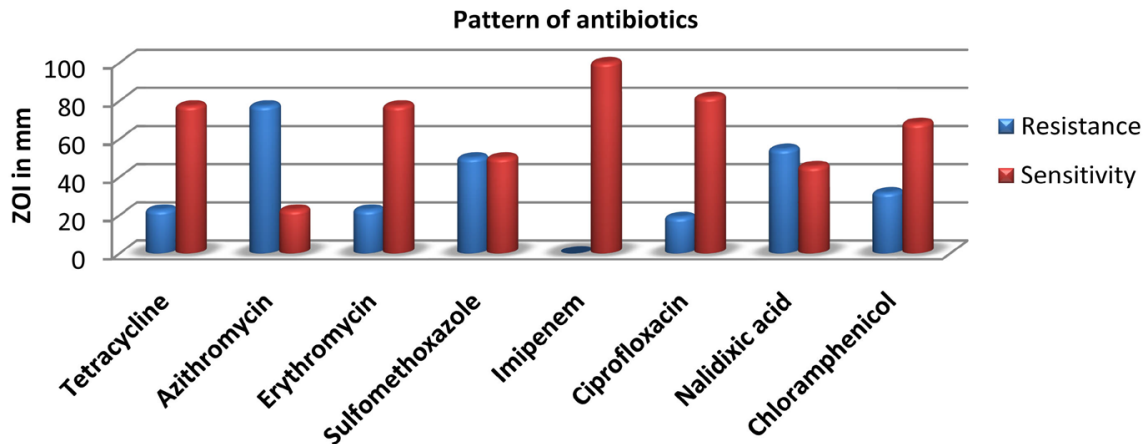

Figure 3. Antibiotics sensitivity pattern of isolates from meat samples from Gazipur area.

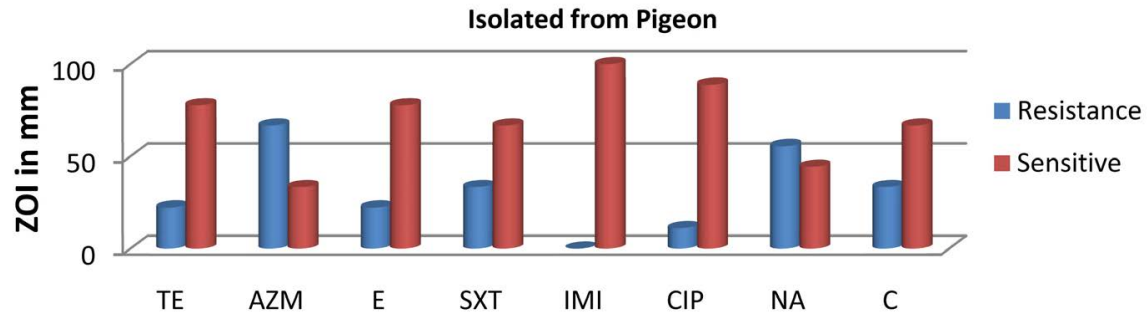

Figure 4. Antimicrobial resistance profiles of Enterococcus species isolated from pigeon. Note: TE = Tetracycline; AZM = Azithromycin; E = Erythromycin; SXT = Sulfomethoxazole; IMI = imipenem; $\mathrm{CIP}=$ Ciprofloxacin; $\mathrm{NA}=$ Nalidixic Acid $\mathrm{C}=$ Chloramphenicol.

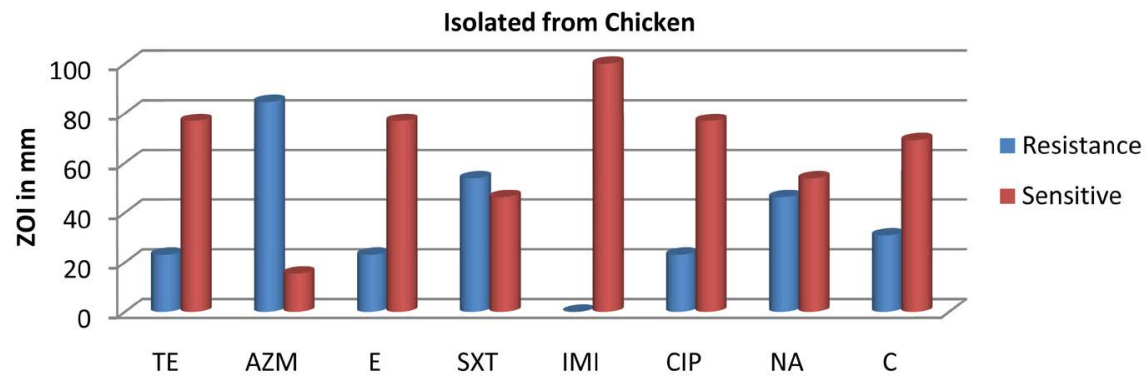

Figure 5. Antimicrobial resistance profiles of Enterococcus species isolated from ChickenNote: $\mathrm{TE}=$ Tetracycline; $\mathrm{AZM}=$ Azithromycin; $\mathrm{E}=$ Erythromycin; $\mathrm{SXT}=$ Sulfomethoxazole; $\mathrm{IMI}=$ imipenem; $\mathrm{CIP}=$ Ciprofloxacin; $\mathrm{NA}=$ Nalidixic Acid; $\mathrm{C}=$ Chloramphenicol. 
process, storage condition, temperature and different type of packing of meat spoilage flora is influenced singularly [20]. The average of the TBC in poultry was $6.34 \log \mathrm{CFU} / \mathrm{gm}$ and the enterococci were $4.83 \mathrm{log} \mathrm{CFU} / \mathrm{gm}$. Comparative results of TBC in $\log \mathrm{CFU} \cdot \mathrm{cm}^{-2}$ were present $4.11 \log \mathrm{CFU} \cdot \mathrm{cm}^{-2}$ and $4.98 \mathrm{log}$ $\mathrm{CFU} \cdot \mathrm{cm}^{-2}$ in previous work [21] [22].

In-vitro antibiotic sensitivity pattern of isolated enteroccus spp. was accomplished against 8 commonly used antibiotics in different groups. After incubation, Zone of inhibition (ZOI) in diameter were measured for individual antibiotics agents which one were highly sensitive, moderately sensitive, less sensitive and resistant (Figure 2).

Among the isolates poultry and pigeon meat samples, Imipenem and Ciprofloxacin wee highly sensitive. Tetracycline, Erythromycin and chloramphenicol were showed moderately sensitive range $80 \%$ to $60 \%$ in isolates. Nalidixic acid was seen less sensitivity against both meats isolates $55 \%$ to $45 \%$. Azithromycin were presented resistance in isolates showed (Figure 3 \& Figure 4). One antibiotic, sulfamethoxazole were showed less sensitive in poultry but showed more sensitivity pattern in pigeon isolates. Rest of the antibiotics exhibited high antimicrobial activity against the isolates.

In $21^{\text {st }}$ century, development and use of antibiotic has been one of the most important steps towards controlling of infectious bacterial disease. The reveals the emergences of the finding antibiotics against Enterococcus spp infection are great suggested in human and environment.

\section{Conclusion}

It is concluded from the present study that public health safety and awareness should be developed to reduce the incidence of Enterococci infection among the people in order to avoid illness. To successfully increasing number of drug sensitive and multi drug sensitive bacteria, extensive knowledge of the molecular mechanisms of acquiring antibiotic and updated information is required.

\section{Limitation of This Study}

Finding in this study indicates Enterococcus can cause food-borne illness in undercooked meat product. Molecular study of isolates needs to be conducted for better understanding of drug resistance mechanism. Also, analysis of meat samples from different location of different district may be helpful for determining of drug resistance pattern. Poultry feed used in farm and comparison of farm raised poultry with home raised one may also exhibit contrast in resistance between isolates.

\section{Conflicts of Interest}

Authors have declared that no competing interests exist.

\section{Authors Contributions}

This work was carried out in collaboration between all authors. Authors KF de- 
signed the study. Author NM and $\mathrm{AB}$ managed the experimental process and analyses of the raw data. Authors $\mathrm{AB}$ and $\mathrm{KF}$ wrote the protocol and the first draft of the manuscript. Author TA managed the literature searches. All authors read and approved the final manuscript.

\section{References}

[1] Jamet, E., Akary, E., Poisson, A.A.J.F., Bertrand-Chamba, X. and Serror, P. (2012) Prevalence and Characterization of Antibiotic-Resistant Enterococcus faecalis in French Cheeses. Food Microbiology, 31, 191-198. https://doi.org/10.1016/j.fm.2012.03.009

[2] Moraes, P.M., Perin, L.M., Todorov, S.D., Silva Jr., A., Franco, B.D. and Nero, L.A. (2012) Bacteriocinogenic and Virulence Potential of Enterococcus Isolates Obtained from Raw Milk and Cheese. Journal of Applied Microbiology, 113, 318-328. https://doi.org/10.1111/j.1365-2672.2012.05341.x

[3] Frankenberg, L., Brugna, M. and Hederstedt, L. (2002) Enterococcus faecalisheme-Dependent Catalase. Journal of Bacteriology, 184, 6351-6356. https://doi.org/10.1128/JB.184.22.6351-6356.2002

[4] Foulquié Moreno, M.R., Sarantinopoulos, P., Tsakalidou, E. and De Vuyst, L. (2006) The Role and Application of Enterococci in Food and Health. International Journal of Food Microbiology, 106, 1-24. https://doi.org/10.1016/j.ijfoodmicro.2005.06.026

[5] Kayser, F.H. (2003) Safety Aspects of Enterococci from the Medicinal Point of View. International Journal of Food Microbiology, 88, 255-262.

https://doi.org/10.1016/S0168-1605(03)00188-0

[6] Poulsen, L.L., Bisgaard, M., Son, N.T., Trung, N.V., An, H.M. and Dalsgaard, A. (2012) Enterococcus faecalis Clones in Poultry and in Humans with Urinary Tract Infections, Vietnam. Emerging Infectious Diseases, 18, 1096-1100. https://doi.org/10.3201/eid1807.111754

[7] Kapoor, L., Randhawa, V.S. and Deb, M. (2005) Antimicrobial Resistance of Enterococcal Blood Isolates at a Pediatric Care Hospital in India. Japanese Journal of Infectious Diseases, 58, 101-103.

[8] Kaszanyitzky, E.J., Tenk, M., Ghidan, A., Fehervari, G.Y. and Papp, M. (2005) Antimicrobial Susceptibility of Enterococci Strains Isolated from Slaughter Animals on the Data of Hungary Resistance Monitoring System from 2001 to 2004. International Journal of Food Microbiology, 115, 119-123. https://doi.org/10.1016/j.ijfoodmicro.2006.10.004

[9] Stalker, M.J., Brash, M.L., Weisz, A., Ouckama, R.M. and Slavic, D. (2010) Arthritis and Osteomyelitis Associated with Enterococcus cecorum Infection in Broiler and Broiler Breeder Chickens In Ontario, Canada. Journal of Veterinary Diagnostic Investigation, 22, 643-645. https://doi.org/10.1177/104063871002200426

[10] Velkers, F.C., van de Graaf-Bloois, L., Wagenaar, J.A., Westendorp, S.T., van Bergen, M.A., Dwars, R.M. and Landman, W.J.M. (2011) Enterococcus hirae-Associated Endocarditis Outbreaks in Broiler Flocks. Clinical and Pathological Characteristics and Molecular Epidemiology, 31, 3-17.

[11] Mongkolchavivat, L. (2011) Bangladesh Remains a Strong Player in Poultry. Outlook Bright despite Effects of Bird-Flu: Experts. Star Business Report. The Daily Star Newspaper. https://www.thedailystar.net/news-detail-188204

[12] Rahman, M.M. and Rahman, A. (1998) Cattle and Poultry Development Activities. In: Karjakrom, K.O., Ed., Directorate of Livestock Services (DLS), Bangladesh, 1, 
31-55.

[13] Akbar, M.A., Amin, M.R., Ali, M.A., Bhuiyan, M.S.A. and Kabir, A.K.M.A. (2013) Animal Husbandry-A Business Education for Today or Tomorrow. 3rd Annual Conference and Seminar-2013, Bangladesh Society for Animal Production Education and Research (BSAPER), Savar, 26 October 2013, 21-34.

[14] Boby, F., Ahmed, S., Paul, S.K., Nasreen, S.A. and Haque, N. (2016) Antimicrobial Susceptibility Pattern of Enterococci Isolated from Clinical Specimens at Mymensingh Medical College Hospital, Mymensingh, Bangladesh. Journal of Bacteriology \& Mycology Open Access, 3, Article Title: 00061.

[15] Cappuccino, J.G. and Sherman, N. (2010) Microbiology A Laboratory Manual. 7th Edition, Pearson Education in South Asia, Singapore, Part 5, 143-203.

[16] Bauer, A.W., Kirby, W.M., Sherris, J.C. and Turck, M. (1966) Antibiotic Susceptibility Testing by a Standardized Single Disk Method. American Journal of Clinical Pathology, 45, 493-496. https://doi.org/10.1093/ajcp/45.4_ts.493

[17] (1999) Approved Standard M31-A. NCCLS Performance Standards for Antimicrobial Disk and Dilution Susceptibility Tests for Bacteria Isolated from Animals. National Committee for Clinical Laboratory Standards, Wayne, $86 \mathrm{p}$.

[18] Steel, R.O.D. and Torrie, J.H. (1980) Principles and Procedures of Statistics. A Biometrical Approach. McGraw-Hill, New York, 633 p.

[19] Franz, C.M.A.P., Stiles, M.E., Schleifer, K.H. and Holzapfel, W.H. (2003) Enterococci in Foods-A Conundrum for Food Safety. International Journal of Food Microbiology, 88, 105-122. https://doi.org/10.1016/S0168-1605(03)00174-0

[20] Labadie, J. (1999) Consequences of Packaging on Bacterial Growth. Meat Is an Ecological Niche. Meat Science, 52, 299-305. https://doi.org/10.1016/S0309-1740(99)00006-6

[21] Krocko, M., Canigova, M. and Duckova, V. (2007) Occurrence, Isolation and Antibiotic Resistance of Enterococcus Species Isolated from Raw Pork, Beef and Poultry. Journal of Food and Nutrition Research, 46, 91-95.

[22] Vaidya, V.M., Paturkar, A.M., Wakar, V.S., Zende, R.J. and Rawool, D.B. (2005) Detection of Indicator Organisms on Poultry Carcass Sites in an Organized Slaughterhouse. Journal of Muscle Foods, 16, 289-297. https://doi.org/10.1111/j.1745-4573.2005.00021.x 